\section{TEACHING THE FORMAL REPORT: THE FIRST UNITS}

L111ta Rodman

\section{INTRODUCTION}

U.B.C.'s English 301, a 13-week course in technical/business writing open to students who have completed freshman English, usually attracts about 1,000 students a year. Since the enrollment is heterogeneous-including students in Science, Pharmacy, Engineering, Physical Education, Forestry, Agriculture, and Commerce, among others--the course has to meet a wide variety of needs. The central assignment, accounting for a third of the grade, is a formal, 2,500-word report on which students work throughout the term. Guiding this work of ten presents a serious problem for beginning instructors. This paper describes my first three units in teaching the formal report: choosing the topic, writing the report proposal, and gathering evidence. These units are normally completed in the first three weeks.

\section{CHOOSING THE TOPIC}

Obviously, chonsing a report topic is an artificial exercise, because in practice, report topics are not chosen, but are assigned as the need for information for decision-making arises. In choosing a 301 report topic, then, the student is finding a topic that someone could realistically request a report on; the instructor's task is to help him locate a sultable topic.

\section{Guldellnes}

To help simulate some of the conditions under which "real" reports are normally written, we have established the following guidelines for the 301 report:

1. It must make recommendations. As a rule, this means that the report will identify problems and suggest solutions.

2. It must be based on the student's own experience and/or investigation; this $1 \mathrm{~s}$ not a library research paper.
3. The claims in the report must be based on verifiable evidence. In other words, the report must be objective, rather than subjective.

\section{Choosing the General Topic}

The three common sources of toplcs are work, hobbles, and the campus or community. Because reports based on work experience tend to be the most successful, the other two sources are used only if the student has no work experience, or if some other factor, such as difficulty in obtaining needed information from the workplace, precludes this choice. Students who have varied work experience are advised to favour the most recent and the most accessible job. For example, someone who has worked on a pipeline in the Northwest Territories and in a restaurant in Vancouver is encouraged to first consider the local fob because conducting a thorough investigation will be much easier if the workplace can be visited. Topics related to hobbies or the community must first be narrowed so that the general area of the topic becomes analogous in scope to a work site. For example, instead of considering "sailing", the student should consider sailing in a particular area, or salling a particular kind of boat, or salling from a particular club.

\section{Narrowing the Topic}

Narrowing the topic consists primarily of identifying the problems or problem areas that the report will discuss. In general, students begin by reflecting on how procedures or equipment or facllities can be $1 \mathrm{~m}-$ proved. I also suggest that they consider schedules, or training programs, or safety measures. As a rule, these suggestions enable about two-thirds of the class to find topics. Students who clalm that their jobs have not been sufficiently interesting or complex to provide them with a topic are encouraged to 11 st all their duties and then to think about how to Improve each step. Topics based on hobbies or the campus can be narrowed using more or less the same kinds of subdivisions to Identify problems. 


\section{Checking for Feasibillty}

After a potential topic has been chosen, it should be tested for feasibility, because an inappropriate choice will lead to wasted time, frustration, and perhaps a poor report. Students should ask themselves the following questions:

1. Am I competent to write the report? Some students want to tackle problems that they can't possibly solve on their own. For example, someone who has worked for a mining company might want to investigate the environmental hazards of dumping waste in a particular place. While the problem is probably most worthy of investigation, it is clearly unrealistic for a student to attempt to explore it in the avallable time. Similar$1 y$, some students will want to attempt "consumer report" topics on the equipment associated with their hobbies; again, they obviously don't have the time, facilities, or expertise to compete with professional assessments.

2. Does the topic lend itself to an objective investigation? Very often students want to focus on personality conflicts or on the personal unsuitability of supervisors. Since these discussions are bound to become very subjective, I suggest that they avoid any discussion of Individuals.

3. Will the needed information be readily accessible? Students who investigate problems at distant work sites can encounter serlous difficulties if they have to rely too much on information that others have to gather and mail to them. Similarly, investigations of community problems can involve lengthy, but fruitless searches. Some of these difficulties can be avolded by altering the topic so as to lessen the dependence on external sources of information. A rather different obstacle is need for information that is confidential. A company does not usually want to disclose unflattering statistics, and a community private hospital is most unlikely to want a stranger "Inspecting" its facilities or interviewing its patients.

\section{Sample Titles}

To provide a clearer idea of potential topics, I circulate and discuss a list of about thirty titles of reports written by previous students, including the following:

1. An Analysis of the Organization of the C.P. Flight Kitchen

2. Saftety Recommendations for the West Vancouver Aquatic Facility

3. Improving the Accuracy and Accessibility of Drawings at Crofton Pulp and Paper Ltd.

4. Improving High School Bassoon Instruction in B.C.

5. Improving Chambermaid Training at the Vancouver Hyatt Regency

6. An Evaluation of Facilities for Handicapped Students at U.B.C.

\section{In-class Memo}

After a very brief explanation of what a memo is, I then give the class ten or fifteen minutes to write memos telling me the potential topics they are considering. This exercise forces the student to make at least an inftial commitment to a topic and gives me an early indication of who will need more help in choosing a suitable topic; my comments on these memos also of course tell each student how I have reacted to the proposed topic(s). I return the memos in the next class and arrange brief interviews with those students who are having trouble finding a topic.

\section{THE REPORT PROPOSAL}

The report proposal, a home assignment due at the end of the second week, is another, longer (about 300 words) memo to the instructor. In introducing the assignment, I note that a memo is usually an in-house document, show some examples of printed memo forms, and explain how and why the form of the memo differs from the form of a letter. The report proposal includes the following headings, each followed by a brief paragraph: statement of purpose, significance, audience, and data base. In addition to requiring students to define the above variables early, this assignment also provides a basis for the "Introduction" section of the report. 


\section{Statement of Purpose}

The statement of purpose has the following form: "In this report I will (verb) the (subject) (modifiers)." For example, "In this report I will evaluate the safety procedures at the Richmond Plywood Plant." The verb must 1mply an analytical approach; examine, evaluate, and analyze are suitable verbs, but describe is not, because by itself it does not imply analysis. The object of the statement of purpose sentence, together with its modifier(s), will be the subject of the report, and should be as spectfic and precise as possible. The rest of the paragraph under this heading indicates the kinds of problems the report will address.

\section{Significance}

This paragraph explains why the report is worth writing. Why are the problems worth solving? What benefits will solving these problems produce? If the problems discussed in the report have been investigated already, how will this report differ from previous ones? The last question is particularly important for reports on hobbies in which students may in some sense be competing with published investigations of the same or similar problems.

\section{Audience}

This paragraph Identifies both the primary and secondary audiences by name and by position in the organization; "management" or "the union" are too vague. Who would assign this report? Who can implement its recommendations? Who will be affected by the recommendations? Who else is likely to be asked to read the report? Students are also encouraged to actually submit a copy to the organization they are writing about, because not only does the offer of a copy of the report of ten make it easier to get information, and sometimes even lead to employment opportunities, but it also seems to help them keep their audiences more firmly in mind and encourages even greater care in the preparation of the report.
The instructor's role as audence of course poses problems. My solution is to suggest that I will read the report, but that I will also route it through the company to the appropriate readers. Obviously, there has to be some pretending on the part of the instructor as well as the student.

\section{Data Base}

This paragraph specifies the evidence that will form the data base of the report. If experience is the major source of information, as it usually 1s, then this paragraph should indicate when and where and in what capacity this experience was obtained. In addition, it should indicate how the information avallable from experience will be supplemented. Will the fob site be visited? Who will be interviewed?

The student may not proceed with any subsequent steps until the proposal has been approved. Evaluating the proposals is critical because approving an unworkable topic will lead to the student wasting time, and the instructor will certainly lose credibility by approving a topic that is later found to be unworkable. The report proposals are marked for adherence to the format guidelines, and for precision, conciseness, clarity and completeness.

\section{GATHERING EVIDENCE}

Most reports are interpretations of verifiable evidence. I spend about one week establishing what is meant by interpretation and verifiable evidence, discussing the steps in designing an investigation, and providing guidelines and suggestions for gathering evidence for the 301 report. Even though most of our students have at least one science course, and many have studied statistics, some are remarkably unprepared to gather data for their reports, perhaps because they fall to recognize the need to apply to the writing task those principles of investigation they already know from other courses. While the discussion of guidelines is completed in the third week, the actual process of gathering evidence will extend for another week or two. 


\section{Verifiable Evidence}

The difference between an interpretation or claim and verifiable evidence can be demonstrated by comparing sets of sentences like the following:

1. The coffee is cold.

2. The beer is warm.

3. The temperature of the coffee is $15^{\circ} \mathrm{C}$.

4. The temperature of the beer is $15^{\circ} \mathrm{C}$.

Clearly, sentences 1 and 2 are subjective and include relative terms, while sentences 3 and 4 are objective and use absolute terms. In reports, evidence is usually used to support claims, and evidence without interpretation is just as undesirable as claims without support.

This discussion of evidence leads rather naturally to a review of sources of evidence, such as direct observation (measuring, counting, weighing, and so on), interviewing, using questionnaires, and using the results of others' investigations (company records, publications, and so on). We discuss the kinds of information each source is most suitable for, and also some of its more obvious limitations.

\section{Designing an Investigation}

In the simplest terms, designing an investigation consists of identifying the data that are needed and determining how to collect them. In other words, the invest1gator selects the questions that need answers and then designs means of answering them. The complexity of the details of these apparently simple steps can be demonstrated by discussing how one would investigate whether the campus parking facllities for bicycles are adequate. The class can frame the specific questions that need to be answered and evaluate the various potential sources of evidence.

\section{Designing the Investigation for the 301 Report}

Only when these basic principles have been established do I turn to discussing how students should gather evidence for their reports. They must now make the general strategy defined in the "Data Base" paragraph of the report proposal much more detailed. Obviously, to identify the specific information they need, they must consider the purpose of the report, the audience, and the information they already have. Also, they must now have a much clearer sense of the scope of the report, and for this reason this step should be undertaken as part of the preparation of a preliminary outline. Bearing all these considerations in mind, they should prepare a list of very specific questions they must answer and indicate precisely how they propose to answer them. In other words, they determine what they must count or measure; whom they must interview with which questions; what kinds of company documents and records they will need to see, and precisely what they will be looking for when they examine them.

Most students will be gathering evidence by visiting the work site, but some will have to rely on telephone calls and letters. Since students tend to procrastinate at this point, it is very important to emphasize the urgency of making the necessary arrangements and getting the information as soon as posstble, and certainly no later than the sixth week. When making arrangements for a visit, they should explain why they need the information, assure the company of relative conf $1-$ dentiality, explain exactly what information they will need, and when they will need 1t. They should also ask permission to take photographs. Gathering evidence by mall usually only works well if the student has a contact person such as a former co-worker who can find the answers for his questions on his behalf. In this case it is wise to use both the telephone and a letter to ensure that all the necessary information is collected and that $1 \mathrm{t}$ is delivered in time.

\section{$\underline{\text { In-class Memo }}$}

At the end of week $4 \mathrm{I}$ assign an in-class memo describing each student's progress in information gathering. This allows me to discuss the basic principles of the brief progress report and also identifies students who are encountering serious problems and those who are simply being negligent. 


\section{Blographical Note}

Lilita Rodman is a senior instructor in the Department of English at U.B.C., where she has taught technical/business writing since 1969 , as well as courses In ESL, remedial composition, advanced composition, Canadian literature, and linguistics. She is particularly interested in style in scientific writing and in the use of graphics in technical discourse.

(Note: this is the first of two articles.) 